\title{
The Compressive Strength of High-Performance Concrete and Ultrahigh-Performance
}

\author{
E. H. Kadri, ${ }^{1}$ S. Aggoun, ${ }^{1}$ S. Kenai, ${ }^{2}$ and A. Kaci' ${ }^{1}$ \\ ${ }^{1}$ Laboratory L2MGC, University of Cergy Pontoise, Rue Eragny Neuville sur Oise, Cergy-Pontoise 9500, France \\ ${ }^{2}$ Geomaterials Laboratory, University of Blida, P.O. Box 270, Blida, Algeria \\ Correspondence should be addressed to E. H. Kadri, el-hadj.kadri@u-cergy.fr
}

Received 28 November 2011; Accepted 22 February 2012

Academic Editor: Nai-Qian Feng

Copyright ( 2012 E. H. Kadri et al. This is an open access article distributed under the Creative Commons Attribution License, which permits unrestricted use, distribution, and reproduction in any medium, provided the original work is properly cited.

The compressive strength of silica fume concretes was investigated at low water-cementitious materials ratios with a naphthalene sulphonate superplasticizer. The results show that partial cement replacement up to $20 \%$ produce, higher compressive strengths than control concretes, nevertheless the strength gain is less than $15 \%$. In this paper we propose a model to evaluate the compressive strength of silica fume concrete at any time. The model is related to the water-cementitious materials and silica-cement ratios. Taking into account the author's and other researchers' experimental data, the accuracy of the proposed model is better than $5 \%$.

\section{Introduction}

The use of silica fume in combination with a superplasticizer is now a usual way to obtain high-strength concretes. The improvement of mechanical properties of concretes with silica fume accounts for the increasing consumption of this admixture in concrete. Furthermore, apart from mechanical properties, the durability of high-performance concretes concerning the most common harmful ions (sulfate, chloride, and seawater) is also improved; indeed the reduction of permeability which is due to the more compact microstructure of concrete slows down the diffusion of ions. Nevertheless various authors point out some drawbacks regarding the use of silica fume in concretes. Among these, the loss of plasticity during the production of concrete and the great sensitivity to plastic shrinkage during the initial curing are the most important. However, researchers seem to disagree about the interpretation of the exact role silica fume plays in the increase of mechanical strengths.

Some authors claim that silica fume improves the strength of the bond between the aggregates and the cement matrix [1-5]. The partial replacement of cement by silica fume increases the strength of mortar and concrete; yet it does not seem to have an important impact on the strength of pure cement paste. To other researchers, however, the positive result due to the admixture of silica fume stems from the increase in strength of the cement matrix $[6,7]$. Researchers also disagree about the definition of the optimal content of silica fume which enables to obtain the highest strengths. To some researchers $[8,9]$, the content is about $15 \%$ whereas to others $[5,10]$ the increase in compressive strength may be reached at $30 \%$ to $40 \%$ of replacement of cement by silica fume.

In this study we aim at defining the influence of the content of silica fume on the compressive strength of concrete. Moreover, we introduce a prediction model of the compressive strength of high perfromance concrete depending on time.

\section{Experimental Procedure}

2.1. Basic Materials. We used two crushed limestone aggregates from the "Boulonnais" region with a granular size of 5-12.5 $\mathrm{mm}$ and $12.5-20 \mathrm{~mm}$.

The compressive strength of the aggregates varies from 140 to $180 \mathrm{MPa}$. Their Saturated Surface Dried (SSD) specific gravity was 2.70 and the absorption of $0.5 \%$. The fine aggregate is composed of a mixture of $50 \%$ of rolled sand from the "Seine" region and $50 \%$ of crushed sand from the "Boulonnais" region. The sand has a specific gravity of 2.65, an absorption of $0.80 \%$, and a fineness modulus of 2.56 . 
Table 1: Physical properties and chemical analyses of cements C and silica fume.

\begin{tabular}{lcc}
\hline Description of tests & $\begin{array}{c}\text { Portland cement } \\
\text { (CPA CEM 52.5) }\end{array}$ & Silica fume \\
\hline Mortar strength & & \\
Compressive strength at: & & - \\
2-days & $35 \mathrm{MPa}$ & - \\
7-days & $50 \mathrm{MPa}$ & \\
28-days & $62 \mathrm{MPa}$ & $89 \%$ \\
\hline Chemical analysis & & $0.3 \%$ \\
$\mathrm{SiO}_{2}$ & $19.8 \%$ & $0.6 \%$ \\
$\mathrm{Al}_{2} \mathrm{O}_{3}$ & $5.14 \%$ & $0.3 \%$ \\
$\mathrm{Fe}_{2} \mathrm{O}_{3}$ & $2.3 \%$ & $1.1 \%$ \\
$\mathrm{CaO}_{\text {total }}$ & $64.9 \%$ & $0.2 \%$ \\
$\mathrm{MgO}_{\mathrm{SO}}$, total & $0.9 \%$ & $1.6 \%$ \\
$\mathrm{~K}_{2} \mathrm{O}$ & $3.4 \%$ & $0.6 \%$ \\
$\mathrm{Na}_{2} \mathrm{O}$ & $1.1 \%$ & $3.2 \%$ \\
$\mathrm{Si}^{\mathrm{Li}}$ & $0.05 \%$ & $2.7 \%$ \\
Insoluble residue & - & - \\
\hline Compound composition & $1.1 \%$ & \\
$\mathrm{C}_{3} \mathrm{~S}$ & $0.2 \%$ & \\
$\mathrm{C}_{2} \mathrm{~S}$ & & \\
$\mathrm{C}_{3} \mathrm{~A}$ & $58 \%$ & \\
$\mathrm{C}_{4} \mathrm{AF}$ & $13 \%$ & \\
\hline
\end{tabular}

The physical properties and chemical analyses of cement and silica fume are given in Table 1.

The silica fume contains $89 \%$ of $\mathrm{SiO}_{2}$ with a density of 2.1 and a bulk density of $600 \mathrm{~kg} / \mathrm{m}^{3}$; its BET-specific area is $18.2 \mathrm{~m}^{2} / \mathrm{g}$. The superplasticiser used is a naphthalene sulphonate condensate with $40 \%$ solids content which has a specific gravity of 1.21 .

In order to get homogeneous samples, we adapted the content of superplasticizer so that the slump remains constant. The slump is about 170 to $200 \mathrm{~mm}$ to get a fluid consistency of concrete.

2.2. Test Details. The mixing parameter for the high strength concretes is presented in Table 2. The mixing procedure to get the concrete samples was as follows.

(1) The dry aggregates, and the cementitious materials (cement and silica fume) were mixed without water for one minute.

(2) Mixing water was added with one third of the volume of superplasticizer, then the mixing was continued for 2 minutes and 30 seconds.

(3) The remaining superplasticizer was added with a last one-minute mixing.

The addition of silica fume was obtained by replacing part of the cement with the same weight of silica fume. The silica fume content was $0,10,20$, and $30 \%$ of the cement weight for all mixtures. Four binder, dosages (cement + silica fume) were experimented: 550, 460, 400, and $310 \mathrm{~kg} / \mathrm{m}^{3}$.

The superplasticizer was added as a weight percentage in relation to the binder and the dosage was determined thanks to the "grout method" [11]. This superplasticizer has a good compatibility with the two cements and was used in several structures made of high strength concrete. The total amount of water in mixtures (including the water in the superplasticizer) was $141 \mathrm{~L} / \mathrm{m}^{3}$.

The concrete was cast in $32 \times 16 \mathrm{~cm}$ cylindrical molds which were filled in two successive stages with a needle vibration. The specimens were stored in their molds for 24 hours at a temperature of $20 \pm 1^{\circ} \mathrm{C}$ and at a relative humidity of $55 \pm 5 \%$. They were then demoulded and cured in limesaturated water at $20 \pm 1^{\circ} \mathrm{C}$ until required for testing. The cylinders were tested in compression with a servohydraulic press (standard AFNOR NF 18-406). Each strength value was the average of the strength of three specimens.

\section{Results and Discussion}

3.1. Evolution of the Compressive Strength. The evolution of the compressive strength for different water-cementitious materials ratios between 1 day and 180 days is represented in Figure 1. It is clear from the curves of Figure 1 that the compressive strength of concrete incorporating $10 \%$ and $20 \%$ sf increases compared to the control concrete without sf. On the contrary at a level of $30 \%$ sf, the strength is slightly lower.

Between one $\left(t_{1}\right)$ and about ten days $\left(t_{d}\right)$, the compressive strength $R$ increases linearly according to the logarithm of time $t$.

$$
R=A+B \log \frac{t_{d}}{t_{1}} .
$$

The $B$ coefficient represents the kinetics of the hydration reaction. For sf concrete the kinetics is activated by the pozzolanic effect of the silica fume which starts early before two days $[12,13]$. The variation of the $B / B O$ ( $B o$ for the control concrete) quotient as a function of $w /(c+$ sf) ratio is shown in Figure 2. It can be observed from the curves that the kinetics of the pozzolanic reaction decreases when the $w /(c+\mathrm{sf})$ ratio increases. It is obvious that the higgest pozzolanic effect is due to $10-20 \%$ sf contents. For 30\%sf the granular dispersion of a great number of sf particles makes up for the pozzolanic effect.

After ten days we notice a reduction regarding the kinetics of the increase in the strength of mixes but the reduction is less important for the control concrete. In the long run, the compressive strength of the control concrete is the same as the $10 \%$ and $20 \%$ sf concretes. Figure 3 shows that the compressive strength increases normally when the $w /(c+\mathrm{sf})$ ratio diminishes; moreover, the influence of the water-cementitious materials ratio is more important than the incorporation of silica fume.

The variation of the ratio $R_{\mathrm{s}} / R$ (control) as a function of the sf content after 28 and 180 days for the four investigated water-cementitious ratios is presented in Figure 4. By 
TABLE 2: Mix proportions and properties of fresh concrete.

\begin{tabular}{|c|c|c|c|c|c|c|c|c|c|}
\hline \multirow[b]{2}{*}{ Mixture w/ $(c+s f)$} & \multirow{2}{*}{$\begin{array}{c}\mathrm{sf} /(\mathrm{c}+\mathrm{sf}) \\
(\%)\end{array}$} & \multicolumn{4}{|c|}{ Batch quantities $\left(\mathrm{kg} / \mathrm{m}^{3}\right)$} & \multirow{2}{*}{$\begin{array}{l}* \mathrm{SP} \\
(\%)\end{array}$} & \multicolumn{3}{|c|}{ Properties of fresh concrete } \\
\hline & & Cement & Silica fume & Fine Agg. & Coarse Agg. & & Slump (mm) & Unit weight $\left(\mathrm{kg} / \mathrm{m}^{3}\right)$ & Air content $(\%)$ \\
\hline \multirow{3}{*}{0.25} & 0 & 550 & 0 & 638 & 1192 & 5.5 & 160 & 2551 & 1.2 \\
\hline & 10 & 495 & 55 & 640 & 1200 & 2.8 & 170 & 2546 & 1.5 \\
\hline & 12 & 440 & 110 & 620 & 1190 & 3.4 & 160 & 2520 & 1.3 \\
\hline 4 & 30 & 385 & 165 & 610 & 1172 & 4 & 170 & 2495 & 1.1 \\
\hline 5 & 0 & 460 & 0 & 688 & 1208 & 2.6 & 180 & 2509 & 1.6 \\
\hline \multirow{3}{*}{0.30} & 10 & 414 & 46 & 682 & 1206 & 1.6 & 190 & 2496 & 1.7 \\
\hline & 20 & 368 & 92 & 674 & 1188 & 2.4 & 170 & 2474 & 1.2 \\
\hline & 30 & 322 & 138 & 670 & 1170 & 2.8 & 170 & 2454 & 0.9 \\
\hline \multirow{4}{*}{0.35} & 0 & 400 & 0 & 744 & 1196 & 1.4 & 160 & 2489 & 1.5 \\
\hline & 10 & 360 & 40 & 734 & 1195 & 1 & 170 & 2476 & 1.4 \\
\hline & 20 & 320 & 80 & 730 & 1176 & 1.6 & 170 & 2456 & 1.1 \\
\hline & 30 & 280 & 120 & 720 & 1165 & 2 & 170 & 2437 & 1.6 \\
\hline \multirow{4}{*}{0.45} & 0 & 310 & 0 & 760 & 1152 & 0.6 & 170 & 2366 & 1.4 \\
\hline & 10 & 279 & 31 & 754 & 1147 & 0.4 & 180 & 2354 & 1.3 \\
\hline & 20 & 248 & 62 & 748 & 1137 & 0.8 & 170 & 2340 & 1.4 \\
\hline & 30 & 217 & 93 & 740 & 1129 & 1 & 170 & 2326 & 0.9 \\
\hline
\end{tabular}

${ }^{*}$ SP: superplasticizer (water + solids), percent by weight of the cementitious materials $(c+s f)$.

TABLE 3: Composition and compressive strength of standardized mortar specimens $4 \times 4 \times 16 \mathrm{~cm}$ (NF P15-451).

\begin{tabular}{|c|c|c|c|c|c|c|c|}
\hline $\mathrm{N}^{\circ}$ mixture & 1 & 2 & 3 & 4 & 5 & 6 & 7 \\
\hline $\mathrm{sf} / \mathrm{c}$ & 0 & 0.1 & 0.15 & 0.2 & 0.25 & 0.3 & 0.4 \\
\hline$w /(c+\mathrm{sf})$ & 0.3 & 0.294 & 0.29 & 0.3 & 0.3 & 0.3 & 0.3 \\
\hline$w(\mathrm{~g})$ & 165 & 150 & 135 & 132 & 132 & 120 & 105 \\
\hline$c(\mathrm{~g})$ & 550 & 510 & 500 & 450 & 440 & 400 & 350 \\
\hline $\operatorname{sf}(g)$ & 0 & 51 & 75 & 90 & 110 & 120 & 140 \\
\hline Sand (g) & 1350 & 1350 & 1350 & 1350 & 1350 & 1350 & 1350 \\
\hline Superpl. (\%) & 1.5 & 1.5 & 2.0 & 2.2 & 2.4 & 2.8 & 3.0 \\
\hline$f c_{28}(\mathrm{MPa})$ & 83 & 102 & 109 & 112 & 114 & 112 & 108 \\
\hline$\alpha(\mathrm{sf} / c)$ & 0.005 & 0.196 & 0.261 & 0.341 & 0.364 & 0.340 & 0.292 \\
\hline
\end{tabular}

analysing the curves we notice that the optimum replacement of cement by sf is around $10-15 \%$ sf. This result is in agreement with the conclusions reached by other investigators $[8,9]$.

However, the percentage of the increase in compressive strength for $10 \%$ sf concretes remains quite low, about a maximum of $15 \%$ after 28 days. Furthermore the increase tends to be less important in the long run.

3.2. Prediction of Strength Development of sf Concretes. The compressive strength of an ordinary concrete after 28 days may be represented by the Bolomey equation [14]

$$
f_{c 28}=K R_{c 28}\left(\frac{C}{E+V}-0.5\right)
$$

where $C$ and $E$ are the mass of cement and water, and $V$ is the air volume. $K$ is a coefficient that depends on the characteristics of aggregates. $R_{c 28}$ is the compressive strength of the standardized mortar after 28 days.
For sf concretes, we present a simple equation of the same type

$$
f_{c 28}=K \frac{1}{\rho_{c}} R_{c 28} \frac{L}{(E+V)},
$$

$\rho_{c}$ is the relative density of the cementitious material and $L$ is the effective cementitious content such as $L=C+\alpha(\mathrm{sf} / c) C$. The function $\alpha(\mathrm{sf} / \mathrm{c})$ represents the contribution of $\mathrm{sf}$ in "equivalent" cement to the compressive strength. We may assume that the efficiency of sf is linked to the presence of cement and only depends on the $\mathrm{sf} / \mathrm{c}$ ratio.

Eventually we obtain the following equation:

$$
f_{c 28}=K R_{c 28} \frac{1}{\rho_{c}} \frac{C}{(E+V)}\left[1+a\left(\frac{s f}{c}\right)\right] .
$$

In order to determine the $\alpha(\mathrm{sf} / c)$ function we, measured the compressive strength on standardized mortar specimens with increasing sf contents.

The composition, the compressive strength at 28 days, and the values of the $\alpha(\mathrm{sf} / \mathrm{c})$ function calculated from (4) are listed in Table 3. 

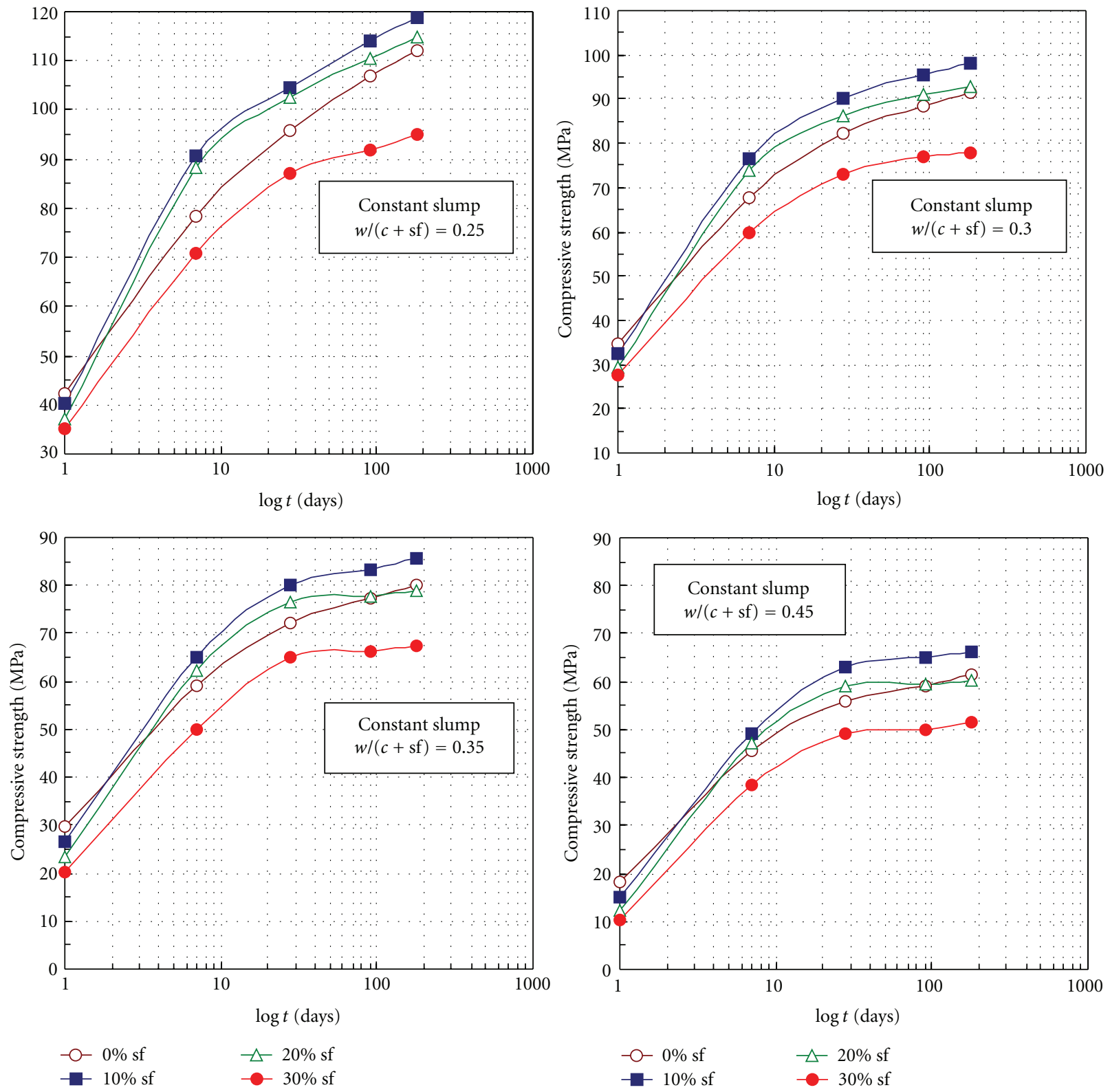

FIGURE 1: Strength development of concretes at different water-cementitious materials ratios.

The curve which represents the variation of the $\alpha$ coefficient with the sf/c ratio is shown in Figure 5. By smoothing the experimental data, the curve can be represented by the following equation obtained with a correlation coefficient of 0.989:

$$
\alpha\left(\frac{\mathrm{sf}}{c}\right)=0.36-\left[2.1\left(\frac{\mathrm{sf}}{c}\right)-0.6\right]^{2}
$$

The air volume of (4) is taken into account by writing $V=y E$. The $y$ coefficient depends on the concrete, consistency according to the following values: 0.13 for a firm concrete, 0.10 for a plastic concrete and 0.07 for a very plastic or fluid concrete [15].
We can generalize the previous equation at any time $t$ by writing

$$
\begin{aligned}
f_{c}(t)= & K R_{c 28} \frac{C}{(y+1) \cdot E} \\
& \times\left\{A(t)+1.36-\left[2.1\left(\frac{\mathrm{sf}}{c}\right)^{2}-0.6\right]^{2}\right\} .
\end{aligned}
$$

The $K$ coefficient depends on the aggregates and will be calculated from the reference concrete strength without sf at 28 days. $A(t)$ is a kinetics function which is determined from the compressive strength of reference concrete at a time $t$ considering that $A(t)=0$ at 28 days.

Figure 6 shows the results obtained by the authors and data related to the works of different researchers. All 


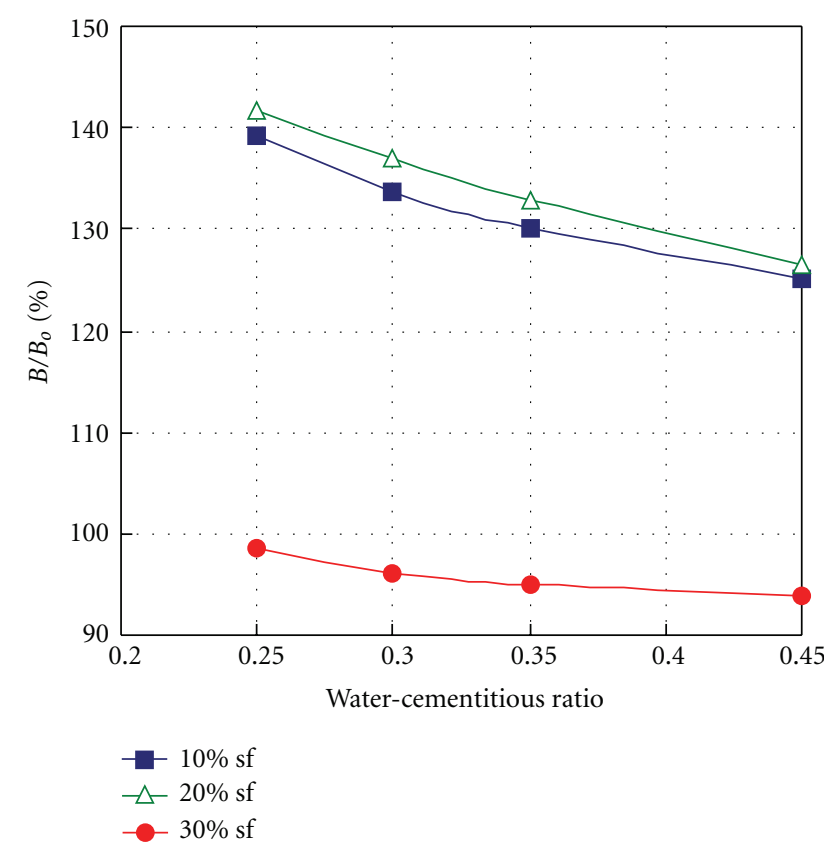

FIGURE 2: Kinetics of the pozzolanic reaction as a function of watercementitious materials ratio.

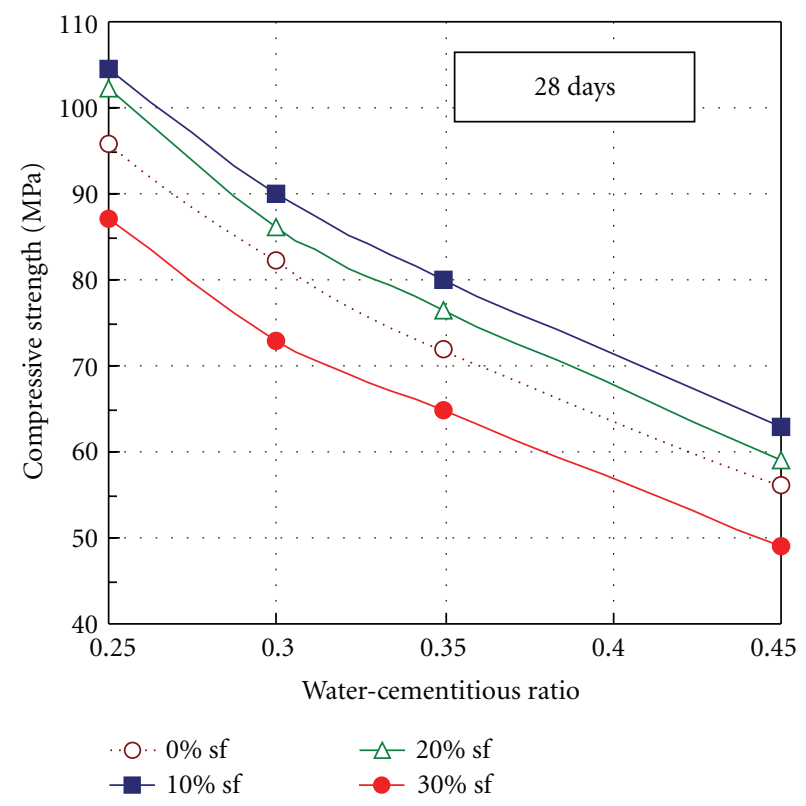

FIGURE 3: Variation of the compressive strength as a function of water-cementitious materials ratio.

the values shown on the curve amount to 282 results [16-29], a good accuracy of the model for predicting the compressive strength of sf concretes is emphasized. The absolute value of the standard deviation between the model and the experimental data is $2.9 \mathrm{MPa}$ with a correlation coefficient of 0.991 . The accuracy is all the more noteworthy as the model does not take into account the nature of silica fume used by the different experimenters. So the amount

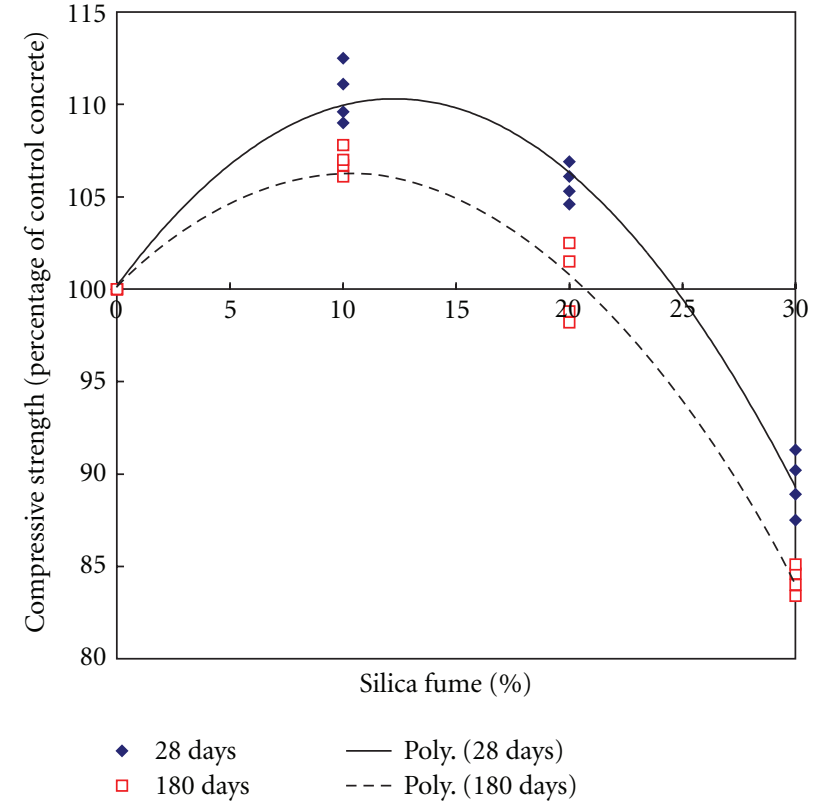

FIGURE 4: Effect of silica fume on compressive strength at different water-cementitious materials ratios.

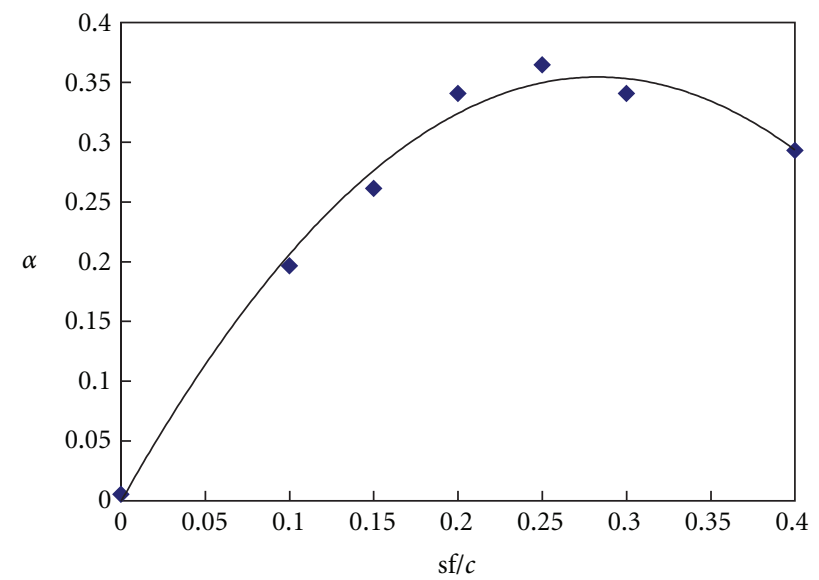

FIgURE 5: Variation of the $\alpha$ funtion with the $s f / c$ ratio.

of $\mathrm{SiO}_{2}$ and oxyd carbon may greatly vary according to the industrial origin of silica fume.

That model may be compared to that obtained by de Larrard [20] which is based on the Feret's law and gives the compressive strength of sf concrete at 28 days

$$
f_{c 28}=\frac{K R_{c 28}}{[1+3.1((E / C) /(1.4-0.4 \exp (-11 \mathrm{sf} / c)))]^{2}} .
$$

The formula is valid for water/cement ratios less than 0.40 .

The comparative results from the two models are shown in Figure 7. The precision is about the same for the application of two models to the 65 experimental values obtained by the authors. 


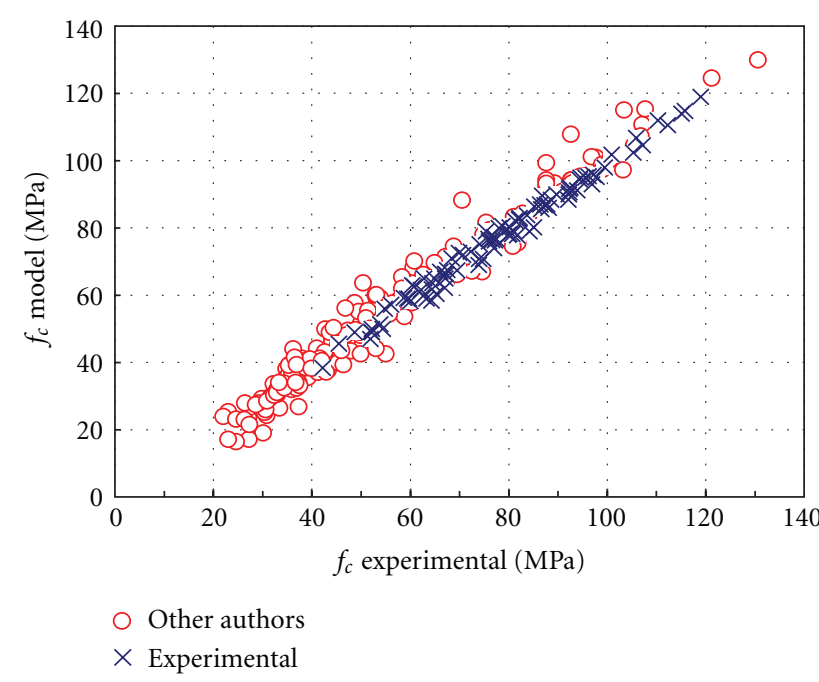

FIGURE 6: Comparison of experimental and theorteical values of the compressive strength at any time.

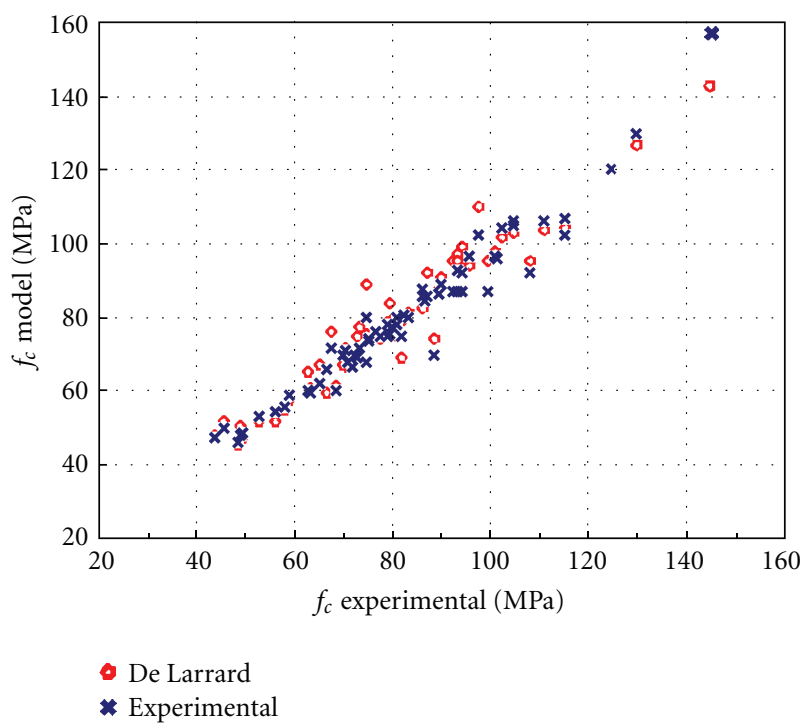

FIGURE 7: Comparison of experimental and theoretical values of the compressive strength at 28 days for the two models.

Moreover Babu and Prakash [30] evaluated the efficiency of silica fume in concrete taking into account a "percentage efficiency factor $k_{p}^{\prime \prime}$ given by the following relation:

$$
k_{p}=0.0015 p_{r}^{2}-0.1223 p_{r}+2.8502,
$$

where $p_{r}$ is the sf percentage compared with the total cementitious.

Insertion of $k_{p}$ in (6) gives

$$
\begin{aligned}
f_{c}(t)= & K R_{c 28} \frac{C}{(y+1) E} \\
\times & {\left[A(t)+1+\left(0.0015 p_{r}^{2}-0.1223 p_{r}+2.8502\right)\right.} \\
& \left.\times \frac{\mathrm{sf}}{c}\right] .
\end{aligned}
$$

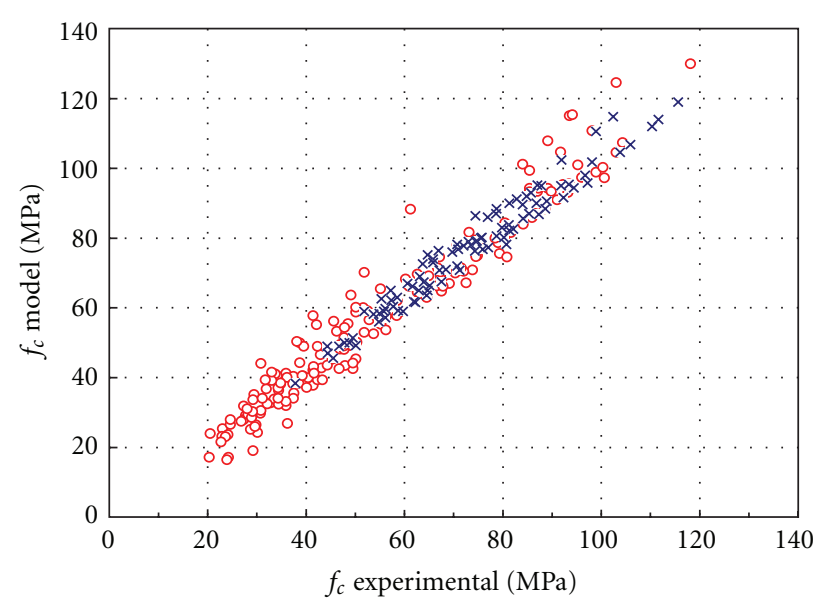

O Other authors

$\times$ Experimental

FIGURE 8: Comparison of experimental and theoretical values of the compressive strength obtained through (9).

Figure 8 shows the comparison of experimental and theorical values calculated from the 282 data with (9). The validation is satisfactory since the absolute value of the standard deviation between the model and the experimental data is $4.3 \mathrm{MPa}$ with a correlation coefficient of 0.979 .

\section{Conclusions}

The increase of the compressive strength of sf concretes depends much more on the decrease of the water/cementitious materials ratio than on the replacement of silica fume with cement. The compressive strength increases with the silica fume content up to $20 \%$ and reaches a maximum for a 10 to $15 \%$ sf level. However, the gain in strength compared with reference concrete remains less than $15 \%$.

Consequently we suggest a model which enables to assess the compressive strength at a given time for sf concretes. After determining the strength of standardized mortar, values of compressive strength are obtained with a correlation coefficient 0.991 thanks to 282 experimental data based on the authors' experiments and other investigations.

\section{References}

[1] A. Goldman and A. Bentur, "Bond effects in high-strength silica-fume concretes," ACI Materials Journal, vol. 86, no. 5, pp. 440-447, 1989.

[2] H. Cheng-yi and R. F. Feldman, "Influence of silica fume on the microstructural development in cement mortars," Cement and Concrete Research, vol. 15, no. 2, pp. 285-294, 1985.

[3] S. L. Sarkar and P. C. Aitcin, "Dissolution rate of silica fume in very high strength concrete," Cement and Concrete Research, vol. 17, no. 4, pp. 591-601, 1987.

[4] J. A. Larbi, "Microstructure of the interfacial zone around aggregate particles in concrete," Heron, vol. 38, no. 1, pp. 1$69,1993$.

[5] H. A. Toutanji and T. El-Korchi, "The influence of silica fume on the compressive strength of cement paste and mortar," 
Cement and Concrete Research, vol. 25, no. 7, pp. 1591-1602, 1995.

[6] X. Cong, S. Cong, D. Darwin, and S. L. McCabe, "Role of silica fume in compressive strength of cement paste, mortar, and concrete," ACI Materials Journal, vol. 89, no. 4, pp. 375-387, 1992.

[7] S. Popovics, "Attempts to improve the bond between cement paste and aggregate," Materials and Structures, vol. 20, no. 1, pp. 32-38, 1987.

[8] V. Yogendran, B. W. Langan, M. N. Haque, and M. A. Ward, "Silica fume in high-strength concrete," ACI Materials Journal, vol. 84, no. 2, pp. 124-129, 1987.

[9] M. N. Sautsos and P. L. J. Domone, "Strength development of low water-binder ratio mixes incorporating mineral admixtures," Utilization of High-Strength Concrete, vol. 2, pp. 945952, 1993.

[10] V. M. Malhotra and G. G. Carette, "Silica fume concreteproperties, applications, and limitations," Concrete International, vol. 5, no. 5, pp. 40-46, 1983.

[11] F. de Larrard, "A method for proportioning high-strength concrete mixtures," Cement, Concrete and Aggregates, vol. 12, no. 1, pp. 47-52, 1990.

[12] E. J. Sellevold and F. F. Radjy, "Condensed silica fume (Microsilica) in concrete: water demand and strength development," Fly-Ash, Silica Fume, Slag and Other Mineral ByProducts in Concrete ACI SP-79, 1983.

[13] J. P. Ollivier, A. Carles-Gibergues, and B. Hanna, "Activite pouzzolanique et action de remplissage d'une fumee de silice dans les matrices de beton de haute resistance," Cement and Concrete Research, vol. 18, no. 3, pp. 438-448, 1988.

[14] J. Bolomey, "Granulation et prévision de la résistance probable des bétons," Travaux, vol. 19, p. 228, 1935.

[15] P. C. Aïtcin, J. Baron, and J. P. Bournazel, "Viser une résistance à la compression," in Dans les Bétons, Bases et Données pour leur Formulation, p. 294, Paris, France, Eyrolles, 1996.

[16] P. C. Aïtcin, "Curing temperature and very high strength concrete," Concrete International, vol. 10, no. 10, pp. 69-72, 1988.

[17] H. H. Bache, "Densified cement ultrafine particle-based materials," in Proceedings of the 2nd International Conference on Super-Plasticizer in Concrete, pp. 185-213, Ottawa, Canada, June 1981.

[18] C. Bedard, G. Ballivy, and P. C. Aïtcin, "Rôle des caractéristiques physico-mécaniques des granulats sur la résistance en compression des bétons à très hautes résistances," Bulletin de l'Association Internationale de Géologie de l'Ingénieur 30, Paris, France, 1984.

[19] G. G. Carette and V. M. Malhotra, "Long-term strength development of silica fume concrete," in CANMET/ACI, Fly, Silica Fume, Slag and Natural Pozzolans in Concrete, vol. 2 of ACI SP132-55, pp. 1017-1044, 1992.

[20] F. de Larrard, "Prévision des résistances en compression des bétons à hautes performances aux fumées de silice ou une nouvelle jeunesse pour la loi de Féret," Annales de l'ITBTP, no. 483, 1990.

[21] J. Djellouli, P. C. Aïtcin, and O. Chaallal, "Use of ground slag in high-performance concrete," in High-Strength Concrete, vol. 2 of ACI SP121-18, pp. 351-368, 1990.

[22] R. Le Roy, Déformations instantanées et différées des bétons à hautes performances, Ph.D. thesis, L'ecole nationale des ponts et chaussées, Paris, France.

[23] V. E. Sorensen, "Freezing and thawing resistance of condensed silica fume (Microsilica) concrete exposed to deicing chemicals," in CANMET/ACI Fly, Silica Fume, Slag and Natural Pozzolans in Concrete, vol. 2 of SP79-37, pp. 709-718, 1983.
[24] V. M. Malhotra, "Mechanical properties and freezing-andthawing resistance of non-air-entrained and air-entrained condensed silica-fume concrete using ASTM test C 666 procedures A and B," in CANMET/ACI, Fly, Silica Fume, Slag and Natural Pozzolans in Concrete, vol. 2 of SP91-53, pp. 10691094, 1986.

[25] S. Seki and M. Morimoto, "Recherche expérimentale sur l'amélioration du béton par l'incorporation de sous-produits industriels," Annales de l'ITBTP, no. 436, 1985.

[26] E. H. Kadri, R. Duval, S. Aggoun, and S. Kenai, "Silica fume effect on hydration heat and compressive strength of highperformance concrete," ACI Journal of Materials, pp. 107-113, 2009.

[27] L. S. Marusin, "Chloride ion penetration in conventional and concrete containing condensed silica fume," in Fly, Silica Fume, Slag and Natural Pozzolans in Concrete, vol. 2 of ACI SP 91-55, pp. 1119-1133, 1986.

[28] O. Skjolsvold, "Carbonation depths of concrete with and without condensed silica fume," in CANMET/ACI, Fly, Silica Fume, Slag and Natural Pozzolans in Concrete, vol. 2 of ACI SP 91-51, pp. 1031-1048, 1986.

[29] J. Wolsiefer, "Ultra high-strength placeable concrete in the range 10.000 to 18.000 psi (69 to $124 \mathrm{MPa}$ )," in Proceedings of the ACI Annual Convention, Atlanta, Ga, USA, January 1982.

[30] K. G. Babu and P. V. S. Prakash, "Efficiency of silica fume in concrete," Cement and Concrete Research, vol. 25, no. 6, pp. 1273-1283, 1995. 

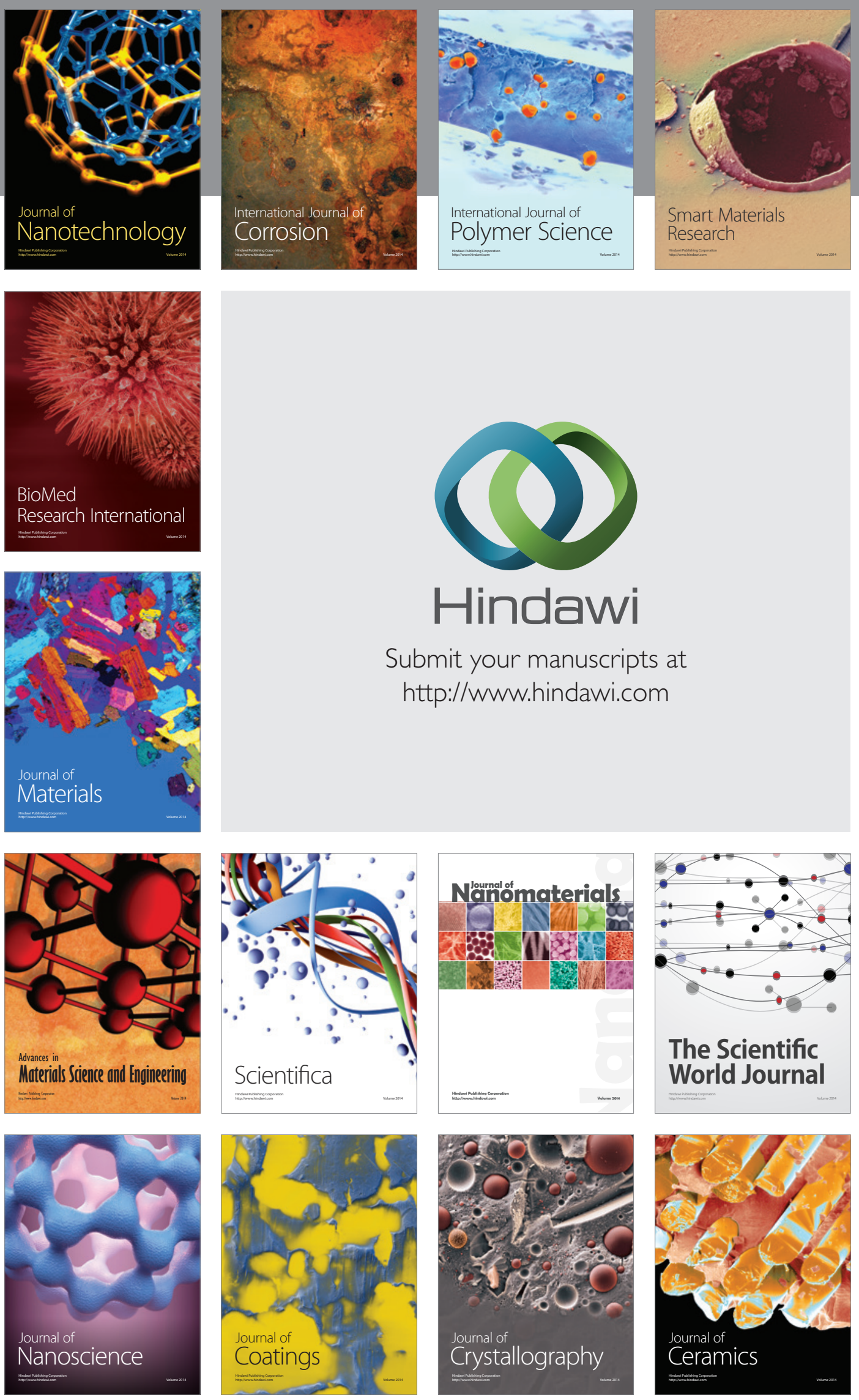

The Scientific World Journal

Submit your manuscripts at

http://www.hindawi.com

\section{World Journal}

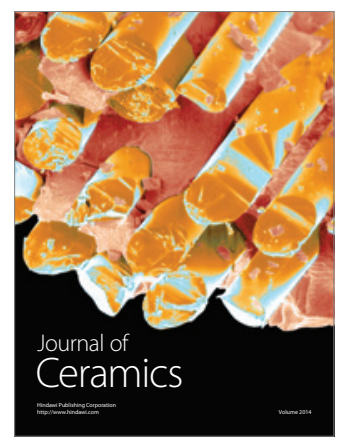

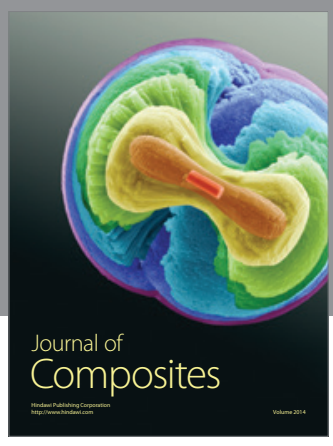
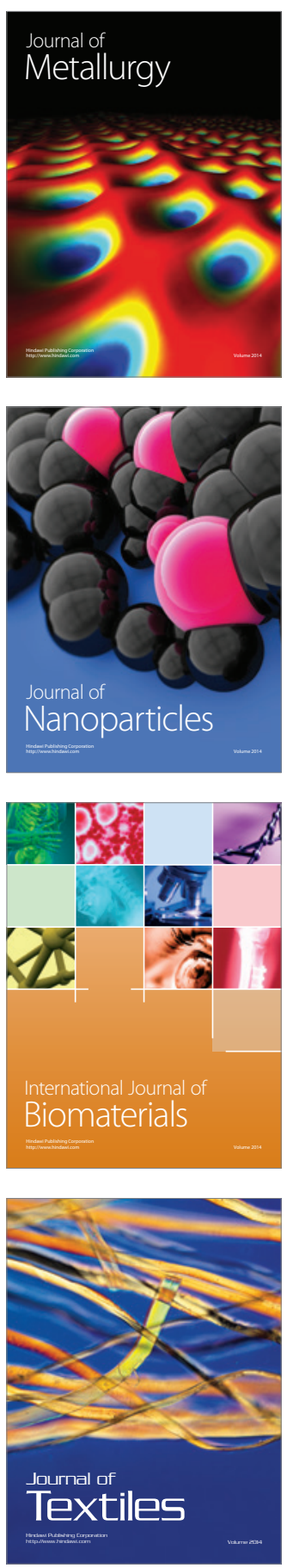